\title{
In Vitro Regeneration of Pongamia pinnata Pierre
}

\author{
K. Sujatha ${ }^{1}$ and Sulekha Hazra ${ }^{1 *}$
}

${ }^{1}$ Plant Tissue Culture Division, National Chemical Laboratory, Pune- 411008, India

\begin{abstract}
Pongamia pinnata Pierre is a tree legume, having potential in production of raw material for biodiesel. A protocol for in vitro propagation of this plant was standardized using seedling explants. Growth regulators (GR) including gibberellic acid $\left(G_{3}\right), N^{6}$-benzylaminopurine(BA), thidiazuron (TDZ), and Adenine sulphate (Ads) were tested for optimum germination of seeds. Removal of seed coat prior to germination, controlled fungal growth partially but enhanced bacterial growth. Antibiotic cefotaxime was ineffective in controlling bacterial contamination. Seedling derived nodal explants and cotyledon nodes with attached cotyledons were excised and cultured for induction of shoots. Optimum sprouting and multiplication of shoot buds were obtained in MS medium supplemented with $8.88 \mu \mathrm{M}$ BA. These buds differentiated and rooted on medium devoid of GR. Optimum growth of Pongamia seedling was obtained in cotton plugged culture vessels. Reculturing of the cotyledon node explants produced more shoots from the same site. This process of removing shoots and reculturing of cotyledon node was followed for eight passages yielding 4 to 8 shoots in each cycle. The shoots $(75 \%)$ rooted on half strength MS basal medium supplemented with $0.22 \%$ charcoal. All plants survived on transfer to soil. This is the first report on in vitro regeneration of Pongamia pinnata. This report demonstrates the possibility of coupling more than one parameter in single experiment to hasten the process of standardization. The process of cycling the nodal explant repeatedly for production of large number of shoots from single meristem may find application in genetic transformation experiments wherein meristems are used for transformation.
\end{abstract}

\footnotetext{
* Corresponding author: e-mail: s.hazra@ncl.res.in

Received Sep. 24, 2006 ; Accepted Dec. 2, 2006
}

\section{Introduction}

To keep pace with the increasing demand of energy and fast diminishing fossil fuel, there is an urgent need to explore all possible approaches to attain optimum production of biofuels. One of the approaches to increase production of biofuels is by increasing the yield of the raw material. The perennial trees like Pongamia pinnata, Jatropa curcas, Maduca indica etc., have high potential in production of biodiesel. These plants need minimum maintenance once planted and yield $25 \%, 37 \%$, and $15 \%$ of oil in the seeds respectively. Clonal propagation of high seed/oil yielding Pongamia pinnata thus is of great significance. Raising plantations or seed orchards of micropropagated plants have definite advantages. Firstly, plantation of trees of selected genotypes is ensured. Secondly possibility of obtaining superior quality seeds is increased and finally the maturation period of the tree is reduced resulting in early seed production.

Pongamia pinnata (popularly known as Karanj in India) is a hardy tree species that mines water for its need from ten meters depths without competing with other crops (Shrinivasa et al. 2002). It grows in various agro climatic conditions from coastline to hill slopes. It has rich leathery evergreen foliage that can be used as green manure. The plant is expected to give economic yields from the 4th year of planting and may continue through its life of hundred years (Shrinivasa et al. 2002). Thus the tree has the potential in phytoremediation of wasteland with economic return. Extensive work has been carried out for physicochemical characterization of Pongam oil (Parmar et al. 1976, Anonymous 1988, Meera et al. 2003) and also for production of biodiesel by transesterification (Vivek and Gupta 2004). However there is no report on tissue culture studies in Pongamia. Methods for micropropagation of $P$.pinnata will find application in propagation of identified high oil/seed yielding trees and also for application of modern gene transfer technologies to plant improvement. Application of biotechnological approaches for genetic manipulation of tree species is often restricted due to their slow growth and recalcitrance in culture. Thus in absence 
of reproducible, de nove regeneration protocols, the existing meristems having potential to regenerate in culture are considered for studies on genetic transformation (Chandra et al. 2003). However explant-associated microbial contaminations and phenolics restricts the use of mature tree derived explant for the purpose of genetic transformation studies. Thus seedling derived axillary meristem has been used for genetic transformation of forest trees (Giri et al. 2004). In vitro raised seedling explants offers the opportunity to use the pair of highly potential cotyledon node explants for transformation studies, in addition to the seedling shoot derived nodes. This report describes a method for in vitro regeneration of shoots from the cotyledon nodes and the nodal buds of the seedlings germinated in vitro of Pongamia pinnata.

\section{Materials and Methods}

\section{Initiation of Cultures}

Dry pods of Pongamia, which dropped from the trees on maturation, were collected from the areas under the trees growing locally. The pods were washed thoroughly in running tap water and air-dried. Seeds were isolated from pods and were washed thoroughly in running tap water. These were treated for $60 \mathrm{~min}$ with $1 \%$ Bavistin (Carbendazim 50\%WP, BASF, India) containing few drops of detergent (Labolene, India), on a gyratory shaker at a speed of $90 \mathrm{rpm}$. This was followed by 3 - 4 washes with sterile distilled water and treatment with $4 \%$ Savion (Johnson \& Johnson, USA) for $10 \mathrm{~min}$. The seeds were treated with $0.1 \% \mathrm{HgCl}_{2}$ for 10 min for surface sterilization. To eliminate adhering $\mathrm{HgCl}_{2}$, the seeds were rinsed repeatedly with sterile distilled water under aseptic condition. These were cultured in bottles containing $50 \mathrm{~mL}$ of Murashige and Skoog's (MS) basal medium (1962) full strength or half strength without growth regulators. Fifty seeds were cultured in each medium formulation and the experiment was repeated twice.

\section{Effect of GRs and Cefotaxime on Germination}

Mature dry pods of Pongamia were collected directly from the tree prior to their natural abscission. The seeds extracted from these pods were surface sterilized by following the method described in the first experiment and were used. The experiment was conducted to determine the influence of (1) minerals and vitamins concentrations, (2) seed coat, (3) antibiotic Cefotaxime and (4) Growth regulators (GRs), in germination of sterile seedlings. Seeds with or without seed coat were cultured in full and half strength MS basal media with varying concentrations of four GRs including $\mathrm{GA}_{3} 0.29,2.89,5.77 \mu \mathrm{M}, \mathrm{BA} 0.44,4.44,8.88 \mu \mathrm{M}$, TDZ 0.45, 4.54, $9.0 \mu \mathrm{M}$, and Ads $0.54,5.43,10.86 \mu \mathrm{M}$. The seed coats were removed after surface sterilization of seeds. Plastic capped glass bottles having $50 \mathrm{~mL}$ medium were used as culture vessel. The experiment was carried out with 7 seeds per treatment and was repeated twice. Antibiotic Cefotaxime, (Taxim, Alkem India Pvt. Ltd) was incorporated $(250 \mathrm{mg} / L)$ aseptically. Nature of contamination and germination frequency was noted after $4 \mathrm{w}$ of incubation. The data or microbial contamination was scored independent of the growth regulator and the observations were grouped as follows: media without Cefotaxime: seeds with seed coat. (C), media without Cefotaxime; seed without seed coat, media supplemented with $250 \mathrm{mg} / \mathrm{L}$ of Cefotaxime; seeds with seedcoa! (CT), and media supplemented with $250 \mathrm{mg} / \mathrm{L}$ of Cefotaxime; seeds without seedcoat (cT).

\section{Optimization of BA Concentration and Selection of Culture Vessell for Shoot Induction and Multiplication}

Keeping in view the effect of BA on Pongamia seed germination in the above experiment and also the literature on supportive role of BA in seed germination (Sandeepkumar et al. 1998; Jain and Babbar et al. 2000; Jordan et al. 2001; Shende et al. 2005), the seeds with coat were cultured in MS basal media without or with various concentrations of $B A$ $(2.22,4.44,6.66$ and $8.88 \mu \mathrm{M})$ to determine the concentration for optimum germination frequency and seedling growth. To identify the appropriate culture vessel both cotton plugged culture tubes and plastic capped jam bottles were used in this experiment. Tubes and bottles containing 20 and $50 \mathrm{~mL}$ medium respectively were used. Single surface sterilized seed was cultured per vessel. For each medium formulation 20 tubes and 15 bottles were used. The experiment was repeated twice. Frequency of germination, length of shoots and number of shoot multiples were noted after 4 weeks of incubation.

\section{Establishment of Shoot Culture}

Shoots were isolated from seedlings germinated in MS basal media supplemented with $0.44 \mu \mathrm{M}$ BA. Nodal segments, $2 \mathrm{~cm}$ in length having one or two node/s were excised from the decapitated shoot. These were cultured in cotton plugged boiling tubes in $20 \mathrm{~mL}$ MS basal media without or with various concentrations of BA $(2.22,4.44$, 6.66 and $8.88 \mu \mathrm{M})$. The frequency of sprouting of axillary buds and number of multiples produced in each culture were scored after 4 weeks of incubation period. The experiment was conducted with 10 replicates in each concentration and was repeated thrice. The shoots obtained from axillary nodes were subcultured for one more passage in the medium of similar composition for further growth. The shoots that attained the length of $2-3 \mathrm{~cm}$ were isolated and tested for rooting and elongation. Whereas the shorter shoots were sub cultured for further growth and multiplication. 


\section{Recycling of Cotyledon Node Explants}

On isolation of shoot from the seedling, the remaining part was the cotyledon node with the pair of cotyledons and the root. The roots were eliminated and the nodal explants, having intact cotyledons were re-cultured in MS basal media supplemented with $0.44 \mu \mathrm{M} B A$ in cotton plugged $250 \mathrm{~mL}$ Erlenmeyer's flasks. Number of shoots produced in each culture and the lengths were noted after 4 weeks of incubation in light. Following this the shoots were excised and either sub cultured for further proliferation or transferred to rooting medium. After excision of shoots the remaining part of the explant with attached cotyledons was re-cultured to induce second crop of shoots. This process of removing the shoots and reculturing the initial explant was repeated for eight cycles.

\section{Rooting of Shoots}

The shoots $2-3 \mathrm{~cm}$ in length, obtained from above experiments, were isolated and cultured in half strength MS basal media supplemented with $0.22 \%$ charcoal. Number of shoots rooted was noted after 4 - 6 weeks of incubation. This experiment was repeated 4 times with 10 to 12 shoots in each batch.

\section{Transfer of Propagules to Soil}

The rooted shoots were removed from culture and washed gently to eliminate agar and sucrose from the roots and were dipped in 1\% Bavistin solution for five min prior to planting in autoclaved sand soil (1:1) mixture in plastic cups. These were covered with transparent plastic sheets and were hardened at $25 \pm 2^{\circ} \mathrm{C}$ in $24 \mathrm{~h}$ photoperiod for 4 weeks. The hardened plants were transferred to bigger pots in greenhouse.

All media used in this study were supplemented with $2 \%$ sucrose and the $\mathrm{pH}$ was adjusted to 5.8, after supplementation with growth regulators. The media were gelled using $0.7 \%$ agar ( $\mathrm{Hi}$ media, India) and were autoclaved at $121^{\circ} \mathrm{C}$ for $20 \mathrm{~min}$ at $1.2 \mathrm{Kg} / \mathrm{cm}^{2}$ All the cultures were incubated for 4 weeks at $25 \pm 2{ }^{\circ} \mathrm{C}$ under $16 \mathrm{~h}$ photoperiod in $25 \mu \mathrm{E} / \mathrm{m}^{2} / \mathrm{s}^{1}$ light intensity unless mentioned otherwise. All data generated from the experiments were subjected to Analysis of Variance (ANOVA) (Panse and Sukhatme 1967).

\section{Results and Discussion}

Many of the difficulties encountered during micropropagation of woody legumes are common to woody plants in general. Major constraint encountered is excessive exudation of phenolics, associated with culture initiation and the recalcitrant nature of shoot or root formation related to the ontogenetic stage of maturity inherent in a perennial woody crop (Trigiano et al. 1992). Success of shoot or root formation in vitro is often related to the maturity of donor plant (Hackett, 1985). Explants obtained from seedlings or plants in juvenile phase of growth have greater potential for organ formation. In absence of literature on tissue culture of $P$. pinnata the seedling explants were used for standardization of the protocol for micropropagation of this species. The information generated from the experiments conducted with the seedling explants can then be extended for the studies on mature trees.

Germination of seeds in vivo is asynchronous thereby restricting the availability of similar explants for experiments on optimization. Secondly germination behaviour of P.pinnata is hypogeal in nature in which the pair of cotyledons with the nodes remains under soil and is infested by microorganisms by the time the seedling grows to a certain size for obtaining nodal explants. To avoid these constraints encountered in using in vivo raised seedlings as the source of explants, attempts were made to standardize the conditions to obtain sterile seedlings of similar age and size.

Initial attempts were made to raise seedlings in vitro using seeds extracted from dry pods, which dropped naturally from the trees on maturation. In spite of the pods being tightly sealed and seeds being covered with hard seed coat, all seeds developed heavy fungal and bacterial contamination in culture preceded by leaching of phenolics. To overcome the heavy contamination, which could be due to adhering of spores in the pods that remained in contact of the ground for several days prior to collection, mature pods of Pongamia were extracted from trees and tested. In spite of using elaborate method of surface sterilization $50 \%$ and $20 \%$ of the seeds developed fungal and bacterial contamination respectively. Some seeds had both fungus and bacteria. Closer examination of the seeds under microscope revealed innumerable grooves and ridges in the seed coat. To eliminate the microbes harbored in these undulations of the seed coat, the seeds with and without coat were tested as explants. Antibiotic, Cefotaxime was incorporated in the medium. This antibiotic have been found effective in controlling bacterial growth in plant tissue cultures of Chrysanthemum (Jaime et al. 2003), Lycopersicon (Raj et al. 2005), Cucumber (Sapounteakis et al. 2002) etc.

There was dramatic increase in the bacterial growth and reduction in fungal contamination on removal of seed coat prior to culture (Figure 1). In view of this result, the possible association of seed coat directly or indirectly in the microbial growth in the Pongamia cultures cannot be ruled out. The possibilities are that (i) the fungal spores were harbored in the seed coat or (ii) there may be factors in the seed coat conducive for growth of fungus. Removal of seed coat thus helped in reducing the fungal contamination. On the contrary, (iii) there may be factors in the seed coat, which prevents bacterial growth. Thus the frequency of ba- 
cterial contamination was high in cultures without seed coat. Pongamia pinnata oil and tissue extracts are known for their antifungal and antibacterial activity (Anonymous 1988; Meera et al. 2003). However there is no specific information on production of antibacterial compound in the seed coat. The bacterial growth in the Pongamia cultures could not be controlled by incorporation of Cefotaxime. Several gram positive/negative bacteria including Bacillus subtilis, B. typhosa, B. paratypii A\&B, Micrococcus pyogenes Var. aureus, Micrococcus pyogenes Var. albus, Micrococcus pyogenes Var. citreus, E. coli, Mycobacterium tuberculosis etc., are sensitive to Cefotaxime. Addition of this antibiotic failed to control the infection (Figure 1) indicating resistance of the bacteria to Cefotaxime.

Overall the frequency of Pongamia seed germination in full strength MS media was higher compared to half strength medium (Table 1). There was no definite pattern noted in the response of the seeds with or without seed coat in media with or without Cefotaxime. Similarly the frequency of germination in various concentrations of $G A$, TDZ and Ads was distributed widely. Thus the response in each instance between the concentration of the GR, seeds with or without seed coat and in presence or in absence of Cefotaxime, could not be correlated. This wide variation in germination frequency in presence of various GRs could be the results of intricacy created by variation in maturity status of the seeds and the multifaceted experimental condition in which the seeds were exposed. The seeds were extracted from the tree on visual assessment of maturity. At all the concentrations of BA, germination frequencies were enhanced irrespective of the other condition of the seed or the media. Optimum response (58.3 \pm $11.7 \%$ ) was noted in seeds with coat in MS basal medium supplemented with BA $0.44 \mu \mathrm{M}$ and in seeds without seed coat in MS basal medium supplemented with BA $8.88 \mu \mathrm{M}$ and Cefotaxime. Thus from the various GRs tested for germination of Pongamia seeds it is apparent that BA was

\section{$\square$ fungal infection $\mathbf{m}$ bacterial infection}

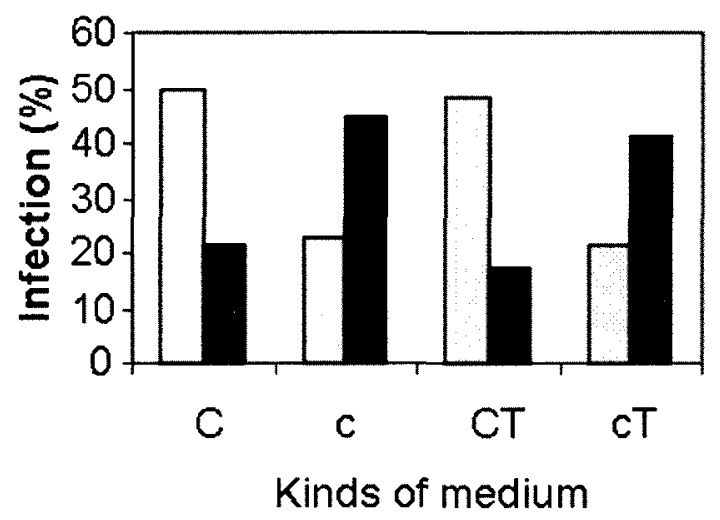

Figure 1. Role of seed coat and Cefotaxime on the extent of fungal and bacterial growth in seedling cultures of Pongamia pinnata. more potent in accentuating Pongamia seed germination. Removal of seed coat or incorporation of Cefotaxime did not demonstrate any obvious effect on frequency of germination. Therefore the following experiment to determine the BA concentration for optimum seedling germination and growth wias conducted with seeds with coat in medium without Cefotaxime.

Tree derived tissues grow slow in culture, the seeds at the right stage of maturation is available only for a limited period annually and z.vailability of vegetative buds at appropriate developmental stage depend largely on the season. By combining 4 parameters in single experiment the need for more number of explants was reduced and the process of standardization was hastened.

The following experiment for optimization of BA concentration was coupled with the experiment for selection of appropriate culture vessel. The frequency of germination (Table 2) in all concentrations of BA was more than control, irrespective of the culture vessel. This indicates the supportive role of $\mathrm{BA}$ on Pongamia seed germination. High $(P<1 \%)$ frequency of response in tubes than in bottles in all the concentrations of $\mathrm{BA}$, suggests that culture vessel with cotton plug provides more supportive microenvironment for growth of Pongamia cultures. In bottles, the leaves were small and only partially opened (Figure 2A). On the contrary the leaves were fully opened and green in the seedlings germinated in tubes (Figure 2B). The medium with $0.44 \mu \mathrm{M}$ BA was oplimum for germination in either culture vessel. In bottles, the germination frequency in medium without GR was $27.4 \pm 8.42 \%$. It increased significantly $(52.8 \pm$ 3.89 ) on supplementing the medium with $0.44 \mu \mathrm{M}$ BA. On further increase of this $\mathrm{GR}(2.22,4.44,6.66,8.88 \mu \mathrm{M})$ there was no significant change. The response varied within 40 $53 \%$. In tubes the germination frequency was $42.9 \%$ in medium without GR and it increased to $76.7 \pm 9.43 \%$ on supplementing the medium with $0.44 \mu \mathrm{M}$ BA. At higher concentrations $(2.22,4.44,6.66,8.88 \mu \mathrm{M})$ there was no further increase in response. Instead there was marginal decrease. Thus optimum germination frequency $(76.7 \pm$ $9.43 \%$ ) was attained in MS medium with $0.44 \mu \mathrm{M} B A$ in cotton-plugged tubes.

Compared to bottles elongation of shoot was significantly higher $(P<5 \%)$ in tubes at all the concentrations of $B A$ tested (Table 2). In the media with or without BA in bottles, the average lengths of shoots ranged between $2.11 \pm 0.88$ to $2.80 \pm 0.75 \mathrm{~cm}$ whereas in tubes it ranged between 3.16 \pm 0.80 to $3.41 \pm 1.05 \mathrm{~cm}$. Thus the optimum elongation of shoot $(3.41 \mathrm{~cm})$ was achieved in medium with $0.44 \mu \mathrm{M} \mathrm{BA}$ in tube. Within the cultures in various concentration of $B A$ either in bottle or in tube there was no significant difference in the average shoot length. This suggests that $0.44 \mu \mathrm{M}$ of BA was optimum for shoot elongation.

The seedlings cultured in medium devoid of GR possessed single shoot whereas in media with BA it was often 
Table 1. Influence of seed coat, Cefotaxime and different growth regulators on germination of Pongamia seeds

\begin{tabular}{|c|c|c|c|c|}
\hline \multirow[b]{2}{*}{ Media* } & \multicolumn{4}{|c|}{ Germination Frequency $(\%)$} \\
\hline & $\underset{\text { mean }}{C} \pm$ sd. & $\begin{array}{c}c \\
\text { mean } \pm \text { sd. }\end{array}$ & $\begin{array}{c}\mathrm{CT} \\
\text { mean } \pm \text { sd. }\end{array}$ & $\begin{array}{c}\mathrm{cT} \\
\text { mean } \pm \text { sd. }\end{array}$ \\
\hline $1 / 2 \mathrm{MS}$ & $8.3 \pm 11.7$ & $27.1 \pm 14.8$ & $12.5 \pm 17.7$ & $8.3 \pm 11.7$ \\
\hline MS & $18.8 \pm 26.5$ & $22.9 \pm 14.7$ & $35.4 \pm 3.0$ & $20.8 \pm 5.9$ \\
\hline $0.29 \mathrm{GA}_{3}$ & $29.2 \pm 5.9$ & $35.4 \pm 3.0$ & $50.0 \pm 0.0$ & $6.3 \pm 8.8$ \\
\hline $2.89 \mathrm{GA}_{3}$ & $35.4 \pm 3.0$ & $14.6 \pm 2.9$ & $20.8 \pm 5.9$ & $29.2 \pm 5.9$ \\
\hline $5.77 \mathrm{GA}_{3}$ & $8.3 \pm 11.7$ & $6.3 \pm 8.8$ & $22.9 \pm 14.7$ & $20.8 \pm 5.9$ \\
\hline $0.44 \mathrm{BA}$ & $58.3 \pm 11.7$ & $50.0 \pm 0.0$ & $35.4 \pm 3.0$ & $56.3 \pm 8.8$ \\
\hline $4.44 \mathrm{BA}$ & $52.1 \pm 20.6$ & $31.3 \pm 26.5$ & $50.0 \pm 0.0$ & $41.7 \pm 11.8$ \\
\hline $8.88 \mathrm{BA}$ & $22.9 \pm 14.7$ & $45.8 \pm 29.4$ & $35.4 \pm 3.0$ & $58.3 \pm 11.7$ \\
\hline $0.45 \mathrm{TDZ}$ & $20.8 \pm 5.9$ & $20.8 \pm 5.9$ & $27.1 \pm 14.8$ & $6.3 \pm 8.8$ \\
\hline 4.54 TDZ & $0.0 \pm 0.0$ & $0.0 \pm 0.0$ & $20.8 \pm 5.9$ & $0.0 \pm 0.0$ \\
\hline $9.0 \mathrm{TDZ}$ & $6.25 \pm 8.8$ & $6.25 \pm 8.8$ & $0.0 \pm 0.0$ & $0.0 \pm 0.0$ \\
\hline 0.54 Ads & $27.1 \pm 14.8$ & $20.8 \pm 5.9$ & $20.8 \pm 5.9$ & $12.5 \pm 17.7$ \\
\hline 5.43 Ads & $16.7 \pm 23.5$ & $20.8 \pm 5.9$ & $20.8 \pm 5.9$ & $22.9 \pm 14.7$ \\
\hline $10.9 \mathrm{Ads}$ & $29.2 \pm 5.9$ & $0.0 \pm 0.0$ & $0.0 \pm 0.0$ & $22.9 \pm 14.7$ \\
\hline Anova & S $5 \%$ & $\mathrm{~S} 5 \%$ & $\mathrm{~S} 1 \%$ & S $1 \%$ \\
\hline
\end{tabular}

*Concentration of $\mathrm{GR}$ in $\mu \mathrm{M}$

C- media without Cefotaxime, seeds with seedcoat;

c- media without Cefotaxime, seeds without seedcoat

CT- media supplemented with Cefotaxime, seeds with seedcoat;

cT- media supplemented with Cefotaxime, seeds without seedcoat.

Table 2. Influence of $N^{6}$-Benzyl amino purine and Culture Vessel on germination frequency of Pongamia pinnata seeds.

\begin{tabular}{|c|c|c|c|c|c|c|}
\hline \multirow{2}{*}{$\begin{array}{c}\text { Conc. } \\
\text { of } \\
\mathrm{BA} \\
(\mu \mathrm{M})\end{array}$} & \multicolumn{2}{|c|}{$\begin{array}{c}\text { Germination Frequency / radicle } \\
\text { emergence }(\%)\end{array}$} & \multicolumn{2}{|c|}{$\begin{array}{l}\text { Average length of shoot }(\mathrm{cm}) \\
\text { mean } \pm \text { sd. }\end{array}$} & \multicolumn{2}{|c|}{$\begin{array}{c}\text { Average number of shoot multiples } \\
\text { mean } \pm \text { sd. }\end{array}$} \\
\hline & Bottles & Tubes & Bottles & Tubes & Bottles & Tubes \\
\hline Control & $27 \pm 8.4$ & $43 \pm 0.0$ & $\begin{array}{c}2.80 \pm 0.8 \\
(05)\end{array}$ & $\begin{array}{c}3.39 \pm 0.9 \\
(10)\end{array}$ & $\begin{array}{c}1.00 \pm 0.0 \\
(05)\end{array}$ & $\begin{array}{c}1.00 \pm 0.0 \\
(10)\end{array}$ \\
\hline 0.44 & $53 \pm 3.9$ & $77 \pm 9.4$ & $\begin{array}{c}2.78 \pm 0.9 \\
(15)\end{array}$ & $\begin{array}{c}3.41 \pm 1.1 \\
(35)\end{array}$ & $\begin{array}{c}1.25 \pm 0.5 \\
(12)\end{array}$ & $\begin{array}{c}1.67 \pm 0.9 \\
(21)\end{array}$ \\
\hline 2.22 & $48 \pm 5.7$ & $75 \pm 0.0$ & $\begin{array}{c}2.75 \pm 0.9 \\
(15)\end{array}$ & $\begin{array}{c}3.37 \pm 1.6 \\
(31)\end{array}$ & $\begin{array}{c}1.15 \pm 0.4 \\
(13)\end{array}$ & $\begin{array}{c}1.55 \pm 0.8 \\
(20)\end{array}$ \\
\hline 4.44 & $40 \pm 4.6$ & $73 \pm 7.1$ & $\begin{array}{c}2.64 \pm 0.7 \\
(09)\end{array}$ & $\begin{array}{c}3.24 \pm 0.9 \\
(16)\end{array}$ & $\begin{array}{c}1.13 \pm 0.34 \\
(8)\end{array}$ & $\begin{array}{c}1.23 \pm 0.4 \\
(13)\end{array}$ \\
\hline 6.66 & $42 \pm 11.8$ & $72 \pm 7.8$ & $\begin{array}{c}2.52 \pm 0.9 \\
(09)\end{array}$ & $\begin{array}{c}3.16 \pm 1.4 \\
(20)\end{array}$ & $\begin{array}{c}1.00 \pm 0.0 \\
(9)\end{array}$ & $\begin{array}{c}1.11 \pm 0.3 \\
(18)\end{array}$ \\
\hline 8.88 & $50 \pm 14.1$ & $67 \pm 18.0$ & $\begin{array}{c}2.11 \pm 0.9 \\
(15)\end{array}$ & $\begin{array}{c}3.16 \pm 0.8 \\
(15)\end{array}$ & $\begin{array}{c}1.00 \pm 0.0 \\
(15)\end{array}$ & $\begin{array}{c}1.0 \pm 0.0 \\
(15)\end{array}$ \\
\hline Two & \multicolumn{2}{|c|}{$(t \times b)$} & \multicolumn{2}{|c|}{$(t \times b)$} & \multicolumn{2}{|c|}{$(\mathrm{t} \times \mathrm{b})$} \\
\hline $\begin{array}{c}\text { way } \\
\text { Anova }\end{array}$ & \multicolumn{2}{|c|}{$\mathrm{S} 1 \%$} & \multicolumn{2}{|c|}{ S5\% } & \multicolumn{2}{|c|}{$\mathrm{S} 1 \%$} \\
\hline
\end{tabular}

* Figures in parenthesis indicate number of replicates

more than one, irrespective of culture vessel. Number of multiples was significantly higher in tubes $(P<1 \%)$ than in bottles and optimum number of shoots $(1.67 \pm 0.86)$ was obtained in MS basal medium with $0.44 \mu \mathrm{M} B A$ in tube. BA is often used for multiplication of shoots in culture (Jain and Babbar. 2000; Fracaro and Echeverrigaray 2001). From the data (Table 2) it is apparent that at the concentration of $0.44 \mu \mathrm{M} B \mathrm{~B}$ in tube, optimum germination frequency, shoot elongation and shoot multiplication was achieved. The cotton plugs in tubes permit exchange of gases and the moisture produced from evaporation of medium escapes through the plugs creating a drier microenvironment for the tissue. On the contrary in bottles the moisture is trapped and the microenvironment of the culture remains saturated with moisture. This is reflected in condensation of moisture on the inner surface of the bottle. Influence of culture 
vessels on growth and development of culture has been emphasized in woody species (McClelland and Smith 1990) and in cotton (Hazra et al. 2000) cultures.

The information generated on the positive role of BA on seed germination, seedling growth and development of multiples, was extended to in vitro raised seedling derived nodal explants to optimize the concentration of BA for induction of multiple shoots. The seedling tip was eliminated and only the nodal buds were used for this exper- iment to maintain uniformity in explants. In medium devoid of $\mathrm{GR}, 97 \%$ of the in vitro raised seedling derived explants responded to sproul and produced one or two shoots whereas all explants $(100 \%)$ responded in cultures supplemented with BA (Table 3). There was increase in number of shoots proliferated from each explant with increase in concentration of $B A$. It increased from $1.7 \pm 1.60$ in $G R$ free medium to $3.77 \pm 4.96$ in medium with $8.88 \mu \mathrm{M} \mathrm{BA}$ (Figure $2 \mathrm{C}$ ). The effect of $\mathrm{BA}$ on proliferation of multiple

Table 3. Influence of BA on shoot multiplication of in vitro raised seedling derived shoot explants of Pongamia.

\begin{tabular}{|c|c|c|}
\hline Conc. of BA $(\mu M)$ & $\begin{array}{l}\text { Freq. of response (\%) } \\
\text { Mean } \pm \mathrm{sd}^{*}\end{array}$ & $\begin{array}{l}\text { No of shoot multiples } \\
\text { Mean } \pm \mathrm{sd}^{*}\end{array}$ \\
\hline Control & $96.7 \pm 5.8$ & $1.70 \pm 1.60$ \\
\hline 2.22 & $100 \pm 0.0$ & $2.03 \pm 2.05$ \\
\hline 4.44 & $100 \pm 0.0$ & $2.40 \pm 1.71$ \\
\hline 6.66 & $100 \pm 0.0$ & $3.40 \pm 1.81$ \\
\hline 8.88 & $100 \pm 0.0$ & $3.77 \pm 4.96$ \\
\hline ANOVA & NS & S5\% \\
\hline
\end{tabular}

* No of replicates 30 in each treatment
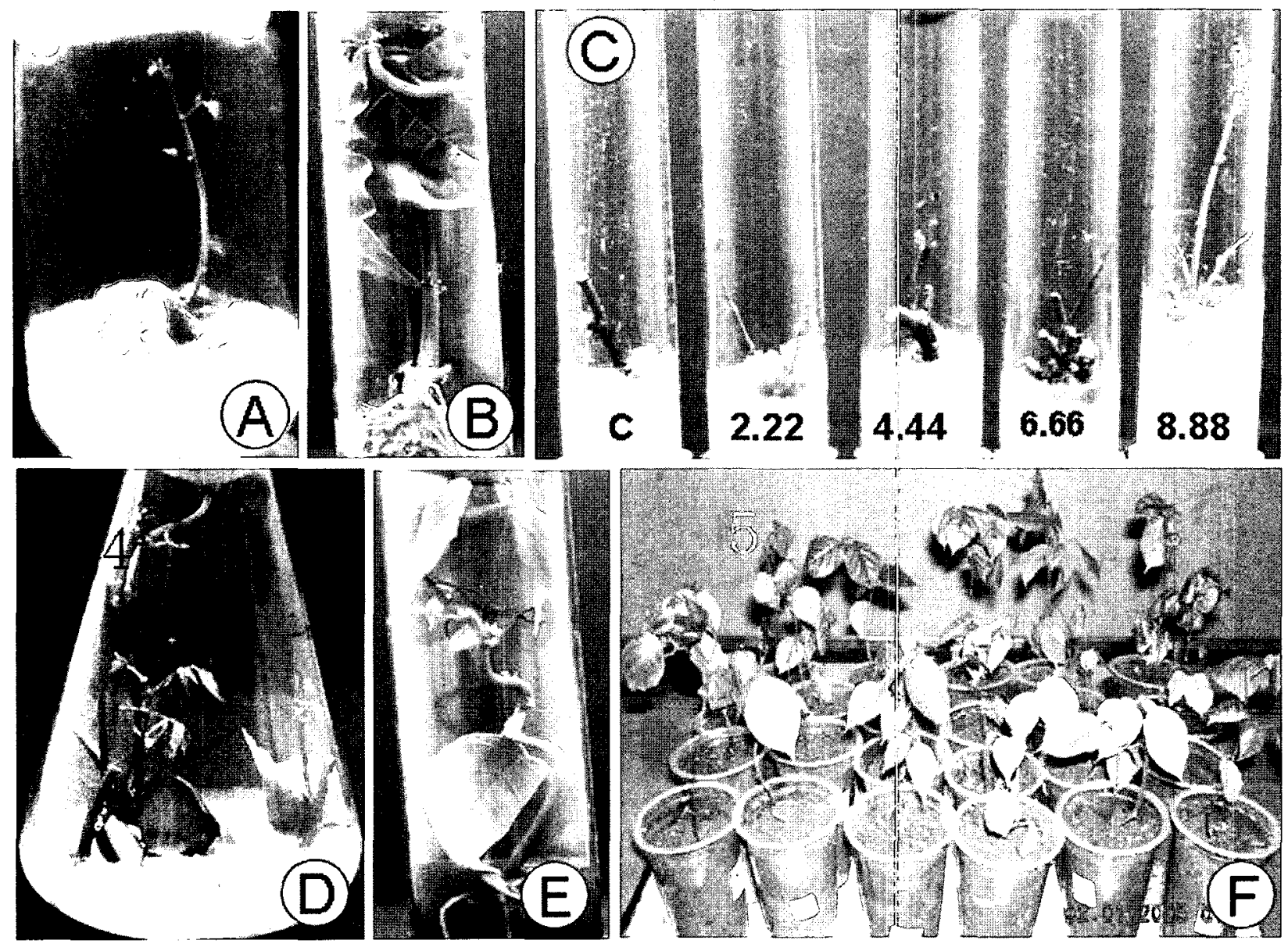

Figure 2. Plant regeneration of Pongamia pinnata. A, Germination of Pongamia seed in bottle. Seedling with diminutive leaves. B, Germination of Pongamia seed in tube. Seedling with fully opened leaves. C, Effect of $B A_{1}(1 \mathrm{M})$ on shoot multiplication on in vitro raised seedling derived nodal explants. Increased number of multiples in higher concentrations of BA. D, Cotyledon node with attached cotyledons in first cycle. Multiple shoots formed from the nodal axil on removal of seedling stem and reculturing the explant. $E$, Differentiation of leaves, elongation and rooting of shoots cultured in half strength $M S$ basal media supplemented with $0.22 \%$ charcoal. F, In vitro regenerated Pongamia pinnata plants hardened for transfer to green house. 
shoot was significant $(P>5 \%)$ and was optimum in medium with BA $8.88 \mu \mathrm{M}$. However, the shoot proliferation in the higher concentration was associated with callusing. To restrict dedifferentiation of the newly formed shoots, use of concentrations of BA higher than $8.88 \mu \mathrm{M}$ was avoided. The shoot buds developed in clusters. These clusters of buds produced more buds on subculture in the medium of similar composition and some of the shoots elongated to 2 $-3 \mathrm{~cm}$.

On removing the shoots and shoot buds from the cotyledon node explant for rooting, elongation and further propagation using the above method, the cotyledon node was treated separately. Culturing of the cotyledon node explant with attached cotyledons for the second time in MS basal media supplemented with $0.44 \mu \mathrm{M} \mathrm{BA}$, produced more caulogenic buds from the same axil, which differentiated to form shoots (Figure 2D). Three to four shoots/seed were produced with an average length of $3.2 \pm 0.98 \mathrm{~cm}$. This process of removing the shoots and reculturing the explants was repeated for 8 cycles. In the third cycle, six to eight shoots were produced with an average length of 3.14 $\pm 0.80 \mathrm{~cm}$. Cycling of original explant provides continual supply of shoots that could either be directed for rooting or for further shoot proliferation.

Shoots and shoot buds obtained from axillary nodes and cotyledon node, proliferated and developed clusters of shoots/buds on subculturing in $\mathrm{BA}(8.88 \mu \mathrm{M})$ containing media. On isolating the shoots and culturing individually in rooting media, the shoots elongated, leaves opened and the root initiated from base (Figure 2E). Out of 48 shoots tested for rooting, 36 shoots rooted in 4 weeks. From the 36 plants transferred to sand: soil (1:1) mixture, 30 plants survived and hardened in 4 weeks (Figure 2F). All hardened plants survived on transfer to pots in green house.

This is the first report on in vitro regeneration of Pongamia pinnata. It describes the protocol for clonal propagation of Pongamia pinnata and also the process of repeated induction of shoots from the same axillary meristem. This process is novel to the best of our knowledge. This report also demonstrates the possibility of combining two or more experiments to hasten the process of standardization. Experimental designs involving several parameters although complex, is useful for standardization of protocol for in vitro studies to hasten the process of standardization particularly in plants in which dearth of initial explant is a major limitation.

Compared to the extensive studies carried out on in vitro regeneration and genetic transformation of herbaceous species the information on tree species is limited for reasons including (i) limited availability of suitable plant material for culture, (ii) recalcitrance, (iii) slow growth, (iv) explant associated microbial contaminations etc. To overcome these limitations in some plant species, the embryo axes and seeds are used for genetic transformation. The protocol described in this report will find application in regeneration of transgenics when the embryo axes or whole seeds are used for genetic transformation (Hany et al. 2002, Chandra and Pental 2003, Raj et al. 2005). The axillary meristems are multicellular structures and genetic transformation is often an event that occurs in single cell. Induction of large number of shoots from the same meristematic tissue will increase the possibility of recovery of the transgenics. Application of this phenomenon for clonal propagation from mature tree derived buds needs to be tested.

\section{Acknowledgements}

We acknowledge C.S.IR. India for the Research fellowship awarded to K. Sujatha.

\section{References}

Anonymous (1988) Raw materials. In Wealth of India Vol.3. CSIR Publications, India, pp. 206-211

Chandra A, Pental D (2003) Regeneration and genetic transformation of grain legumes: An overview. Curr Sci 84: 381-387

Fracaro F, Echeverrigaray S (2001) Micropropagation of Cunila galioides, a popular medicinal plant of south Brazil. Plant Cell Tiss Org Cult 64: 1-4

Giri CC, Shyamkumar B, Anjaneyulu (2004) Progress in tissue culture, genetic transformation and application of biotechnology to trees: an overview. Trees 18: 115-135

Hackett WP (1985) Juvenility, maturation and rejuvenation in woody plants. Hort Rev 7: 109-155.

Hany AE, Khalafalla M, Wakasa. K, Ishimoto, M (2002) Reproducible transformation in two grain legumes- soyabean and azuki bean-using different systems. Cell Mol Bio Lett 7: 709-719

Hazra S, Kulkarni AV, Nalawade SM, Banerjee AK, Agarwal DC, Krishnamurthy KV (2000) Influence of explants, Genotypes and culture vessels on sprouting and proliferation of pre-existing meristems of cotton (Gossypium hirsutum L. and Gossypium arboreum L. In Vitro Cell Dev Biol-Plant 36: 505-510

Jain N, Babbar SB (2000) Recurrent production of plants of black plum Syngium cumini (L.) Skeels, a myrtaceous fruit tree, from in vitro cultured seedling explants. Plant Cell Rep 19: $519-524$

Jaime A, Teixeira da Silva, Fukai S (2003) Chrysanthemum Organogenesis Through Thin Cell Layer Technology and Plant Growth Regulator Control. Asian J Plant Sci 2: 505-514

Jordan M, Larrain M, Tapia A, Roveraro C (2001) In Vitro regeneration of Sophora toromino from seedling explants. Plant Cell Tiss Org Cult 66: 89-95

McClelland MT, Smith MAL (1990) Vessel type, closure and explant orientation influence in vitro performance of five woody species. Hort Sci 25: $797-800$ 
Meera B, Kumar S, Kalidar SB (2003) A review of the chemistry and biological activity of Pongamia pinnata. J Med Aro Plant Sci 25: 441-465

Panse VG, Sukhatme (1967) Statistical analysis for Agricultural Workers. ICAR publications, India

Parmar BS, Sahrawat KL, Mukerjee SK (1976) Pongamia glabra: Constitutents and uses. J Sci Ind Res 35: 608-611

Raj SK, Singh R, Pandey SK, Singh BP (2005) Agrobacterium-mediated tomato transformation and regeneration of transgenic lines expressing Tomato leaf curl virus coat protein gene for resistance against TLCV infection. Curr Sci 88: 1674-1679

Sandeepkumar, Sarkar AK, Kunhikannan C (1998) Regeneration of plants from leaflet explants of tissue culture raised safed Siris (Albizzia procera). Plant Cell Tiss Org Cult 54: $137-143$
Sapounteakis G, Tsaflasris AS (2002) In vitro regeneration and genetic transformation of parthenocarpic Cucumber hybrids. Acta Hort 579: 77-82

Shende S, Rai M (20105) Multiple shoot formation and plant regeneration of $\varepsilon$ commercially useful tropical plant, Buchanania lanzan (spreng). Plant Biotechnol 22: 59-61 Shrinivasa U, Viswanath (2002) Dr. U. Shrinivasa dreams of a biodiesel future biased on Pongamia pinnata. Website: wysiwyg://14http://www.goodnewsindia.com/pages/content/dis covery honge.html.

Trigiano RN, Geneve RL, Merkle SA, Preece JE (1992) Tissue and Cell culture of woody legumes. Hort Rev 14: 265-332

Vivek, Gupta AK (2004) Biodiesel production from Karanja oil. J Sci Ind Res; 63: 39-47 